\title{
BMJ Open Intimate partner violence during pregnancy in relation to non-psychotic mental health disorders in Rwanda: a cross-sectional population-based study
}

\author{
Akashi Andrew Rurangirwa, ${ }^{1,2}$ Ingrid Mogren, ${ }^{3,4}$ Joseph Ntaganira, ${ }^{1}$ \\ Kaymarlin Govender, ${ }^{5}$ Gunilla Krantz ${ }^{2}$
}

To cite: Rurangirwa AA, Mogren I, Ntaganira J, et al. Intimate partner violence during pregnancy in relation to non-psychotic mental health disorders in Rwanda: a cross-sectional populationbased study. BMJ Open 2018;8:e21807. doi:10.1136/ bmjopen-2018-021807

- Prepublication history for this paper is available online. To view these files, please visit the journal online (http://dx.doi org/10.1136/bmjopen-2018021807).

Received 19 January 2018 Revised 5 April 2018 Accepted 9 May 2018

\section{Check for updates}

${ }^{1}$ Department of Epidemiology and Biostatistics, School of Public Health, University of Rwanda, Kigali, Rwanda ${ }^{2}$ Section of Epidemiology and Social Medicine (EPSO), Department of Public Health and Community Medicine, The Sahlgrenska Academy at University of Gothenburg, Goteborg, Sweden

${ }^{3}$ Department of Clinical

Sciences, Obstetrics and Gynecology, Umeå University, Umeå, Sweden

${ }^{4}$ Judith Lumley Centre, La Trobe University, Melbourne, Victoria, Australia

${ }^{5}$ Health Economics and HIV/ AIDS Research Division (HEARD), Universityof KwaZulu-Natal, Durban, South Africa

Correspondence to

Dr Akashi Andrew Rurangirwa; rakashi@nursph.org

\section{ABSTRACT}

Objectives To investigate the prevalence of non-psychotic mental health disorders (MHDs) and the association between exposure to all forms of intimate partner violence (IPV) during pregnancy and MHDs.

Design Cross-sectional population-based study conducted in the Northern Province of Rwanda and Kigali city.

Participants and settings Totally, 921 women who gave birth $\leq 13$ months before being interviewed were included. Simple random sampling was done to select villages, households and participants. Community health workers helped to identify eligible participants and clinical psychologists, nurses or midwives conducted face-toface interviews. The collected data were analysed using descriptive statistics and bivariable and multivariable logistic regression modelling

Results The prevalence rates of generalised anxiety disorder, suicide ideation and post-traumatic stress disorder (PTSD) were 19.7\%, 10.8\% and 8.0\%, respectively. Exposure to the four forms of IPV during pregnancy was highly associated with the likelihood of meeting diagnostic criteria for each of the non-psychotic MHDs investigated. Physical, psychological and sexual violence, showed the strongest association with PTSD, with adjusted ORs (aORs) of 4.5, 6.2 and 6.3, respectively. Controlling behaviour had the strongest association with major depressive episode in earlier periods with an aOR of 9.2 .

Conclusion IPV and MHDs should be integrated into guidelines for perinatal care. Moreover, communitybased services aimed at increasing awareness and early identification of violence and MHDs should be instituted in all villages and health centres in Rwanda. Finally, healthcare providers need to be educated and trained in a consistent manner to manage the most challenging cases quickly, discreetly and efficiently.

\section{INTRODUCTION}

Mental health disorders (MHDs) continue to increase with serious consequences for people's health and well-being worldwide. ${ }^{12}$ More women are affected with MHDs than men, and the impact is especially severe
Strengths and limitations of this study

- Validated data collection instruments were used for investigating non-psychotic mental health disorders and intimate partner violence.

- A large sample size and few non-response rate.

- Detailed sociodemographic and psychosocial characteristics were available.

- The study is cross-sectional, consequently we are unable to draw any causal inferences.

- Due to the sensitive nature of the intimate partner violence and mental health disorders, under-reporting of some events cannot be ruled out.

during pregnancy and the postpartum period as they directly increase maternal and neonatal morbidity and mortality. ${ }^{13}$ Maternal physiological changes lead to elevated susceptibility to MHDs during and after pregnancy. ${ }^{4}$ Furthermore, women suffering from mental health conditions during the perinatal period are at an increased risk of the inadequate use of maternal health services. ${ }^{5}$ Globally, depression is the most common MHD affecting pregnant women and has been the main research focus on perinatal mental health. ${ }^{16}$ However, evidence shows that other disorders such as anxiety and post-traumatic stress disorder (PTSD) are also common and lead to substantial comorbidity with depression. ${ }^{67}$ The adverse effects of women's poor mental health during pregnancy and after childbirth on their developing infants are severe: conditions such as low birth weight, malnutrition, infectious diseases and death in extreme cases may arise, especially in resource-constrained settings. ${ }^{89}$

Higher prevalence rates of MHDs in women during and after pregnancy have generally been reported from low/middle-income countries (LMICs) than from high-income countries (HICs). ${ }^{10}$ The prevalence of depression or anxiety is about $16 \%$ in pregnant 
women and even higher after childbirth (about $20 \%$ in LMICs). ${ }^{1}$ The effects are exacerbated in resource-limited settings because of women's vulnerable life circumstances (eg, low socioeconomic status, insufficient social support and exposure to gender inequality). ${ }^{11-13}$ Additionally, violent traumatic events (eg, conflicts and intimate partner violence, IPV), which are more prevalent in LMICs than in HICs, have been widely associated with MHDs. ${ }^{14} 15$ The situation may be worse in that the disorders may go undiagnosed or mismanaged because of gaps in knowledge and attitude among healthcare providers and the public in general. ${ }^{216}$ The suffering and economic costs this causes women and their families may be so unbearable that they may commit suicide. ${ }^{17}$

The devastating genocide against the Tutsi in Rwanda in 1994 during which an estimated 800000 people were killed has inevitably contributed to the increase in MHDs that have been reported several years after the genocide. ${ }^{18-20}$ The genocide may have also contributed to barriers and challenges that have been observed in seeking mental healthcare.$^{21}$ Apart from the genocide and its effects, many other factors, not least IPV, may underlie this increase in MHDs. IPV refers to behaviour by an intimate partner (or expartner) that causes physical, sexual or psychological harm, including physical aggression, sexual coercion, psychological abuse and controlling behaviour. ${ }^{22}$ In this research programme, we have shown in an earlier study that different forms of IPV are common during pregnancy among Rwandan women. ${ }^{23}$ Most previous studies about the relationship between violence against pregnant women and MHDs in low-income countries (LICs) have investigated the prevalence rates and associations in general population samples and included a few forms of IPV and non-psychotic MHDs. ${ }^{1024-27}$ It is also not known whether prevalence rates of MHDs attributed to IPV vary between pregnant women and the rest of the population. Therefore, this study aimed to assess the prevalence of non-psychotic MHDs in women who gave birth 1-13 months before the interview. A further aim was to study the association between different forms of IPV exposure during pregnancy and non-psychotic MHDs.

This study is part of the Maternal Health Research Programme undertaken by the University of Rwanda (UR) in collaboration with the University of Gothenburg and Umeå University in Sweden.

\section{METHODS}

\section{Study design, study population and sample size}

This cross-sectional population-based study was conducted in the Northern Province and in Kigali city, the largest city in Rwanda. Kigali has urban, semiurban and rural areas, whereas the Northern Province is predominantly rural. The target population was women who gave birth 1-13 months before the interview. The sample size was calculated according to the estimated prevalence of hypertensive disorders during pregnancy, as hypertension is one of the major factors to be investigated within this research programme and was the least prevalent disorder among study outcomes. ${ }^{28}{ }^{29}$ The desired level of precision was set at 0.025 , and a design effect of 1.5 was applied to account for the multistage nature of the study. Thus, after adding $10 \%$ to the sample size for possible non-responses, the final sample comprised 921 women. The selection process was based on the total population of about 2865000 inhabitants from 4791 villages in the study area. ${ }^{30}$ The selection process involved three steps. First, the villages were randomly selected proportionate to the total number of villages in each district by using Epi-Info random function. Second, the number of households from each village was selected based on the total number of households in each selected village (proportionate to size). Finally, with the help of community health workers (CHWs) who keep maternal records, the list of all eligible women from each village was compiled. From the list, the women to be interviewed were randomly selected and thereafter visited in their households for the interview. Random selection was used if more than one eligible woman was present in the household. If an eligible woman was not present at the time of interview, the team waited for her to come or went back later to do the interview at the earliest possible time. In case of fewer eligible women in the village than envisaged in the study, the closest village was approached and the same data collection procedures were used to obtain the remaining number of eligible women. The supervisors ensured that all selected women were contacted and reviewed the filled-in questionnaires before the team left the village. The overall response rate was $99.9 \%$ (one woman refused to be interviewed).

\section{Data collection procedures}

Data collection took place between July and August 2014. A structured, paper-based interviewer-administered questionnaire, including sociodemographic and psychosocial characteristics, items related to IPV and non-psychotic MHDs, was developed. All the data collection instruments were translated into Kinyarwanda, the Rwandan national language, and pretested; no major changes were made apart from a few minor adjustments in Kinyarwanda wording. Twelve well-trained interviewers, who were all female, clinical psychologists, nurses or midwives belonging to a pool of interviewers at the School of Public Health (SPH), UR, carried out face-to-face interviews with the participating women. All the interviews, ranging from 40 to $65 \mathrm{~min}$, took place in the participants' homes. Four supervisors (first author and three colleagues) guided the interviews. If an eligible woman was not present at the time of interview, the team waited for her to come home or returned later to do the interview. The SPH at UR was the lead implementer of the study. Data entry was performed by four skilled personnel from a permanent cohort of data entry clerks from the SPH under the supervision of a data entry manager. Very few errors were detected, and these were corrected after checking the accuracy of the first data entry. The procedure has been described elsewhere. ${ }^{23}$ 


\section{Measures and instruments}

MHD assessment

The Mini International Neuropsychiatric Interview (MINI) version 5.0.0 developed to explore disorders according to Diagnostic and Statistical Manual of Mental Disorders fourth edition was used to identify non-psychotic MHDs. The MINI requires little time to administer and was developed to meet the need for a short but precise structured interview. It does not necessarily require clinical staff to use, has been shown to be a reliable and valid instrument and has previously been successfully used for similar studies in Rwanda. ${ }^{31}$ Four non-psychotic MHDs were assessed and used as the outcome variables: major depressive episodes during the past 2 weeks before the interview and earlier in life ( $\geq 2$ weeks before the interview), generalised anxiety disorder (in the past 6 months), suicidal ideation (anytime in life) and PTSD current (in the past month). The major depressive episodes, generalised anxiety disorder and PTSD sections of the MINI start with two screening questions corresponding to the main criteria of the disorder and end with a yes/no diagnostic conclusion indicating whether the disorder was present. Suicide ideation section of the MINI had six questions, all with yes/no options, that is, did you think that you would be better off dead or wish you were dead, want to harm yourself, think about suicide, have a suicide plan, attempt suicide, ever make a suicide attempt? Diagnosis was reached when at least one question had a yes answer. A summary measure was constructed from the four MHDs and later dichotomised into having at least one of the MHDs (experienced a MHD) or having none (did not experience a MHD). This measure was then used to assess the relationship between participants' sociodemographic characteristics with an MHD experience.

\section{IPV assessment}

$I P V$ during pregnancy was measured as exposure to four forms of violence: physical violence (six items), sexual violence (three items), psychological abuse (four items) and controlling behaviour (seven items). The items for investigating violence were selected from the Women's Health and Life Experiences Questionnaire, a validated questionnaire developed by the WHO for research on IPV experience. ${ }^{32} 33$ This instrument has been shown to be cross-culturally valid and has previously been successfully used for similar studies in Rwanda. ${ }^{25}$ Women were asked to indicate whether they had been exposed to any of the four forms of violent acts during pregnancy. Subsequently, summary measures for each of the forms of violence were constructed. For each of the forms of violence, women who reported yes on any of the items were considered as having experienced violence during pregnancy and were designated as the exposed group in the analyses.

Assessment of sociodemographic and psychosocial characteristics Information about participants' sociodemographic and psychosocial characteristics was obtained by a paper-based interviewer-administered questionnaire. Participants' age was categorised into two age groups: 15-30 and 31-46. Marital status was dichotomised into married or cohabitating (reference category) and then single, divorced or widowed were combined in the exposure category. Women's highest attained level of education was assessed as three items: incomplete primary school (including very few who did not go to school at all), complete primary school or vocational training and complete secondary school, university or any other higher institution of learning. The last category was then used as the reference group in the analyses. Total household monthly income was recorded into a three-category variable as less than or equal to Francs Rwandais (FRW) $17500(\leq \$ 30)$, from FRW17501 to FRW35999 (\$30-\$60) and $\geq$ FRW36000 $(\geq \$ 60)$ and which was later dichotomised into $\leq$ FRW17500 and $\geq$ FRW17501. Social support was assessed as having a family member, a relative or a friend who could lend support to the woman if any need or problem would arise (six items). Each of the items was responded to with four response options (always, often, sometimes and never). These were later combined into yes (always, often and sometimes) and no (never) response alternatives. Subsequently, a summary measure for social support was created and dichotomised into good social support (having responded always, often or sometimes on at least one of the items) and poor social support (having responded never to all the items). Partner's age was categorised into $\leq 40$ years and $41-70$ years age groups. A similar technique as described above for participants was used to categorise partner's highest attained level of education. A composite variable of assets in the household was used as a proxy for socioeconomic status of the household. Assets in the household included a radio, a television set, a refrigerator, a bicycle, a motorcycle, a car, a mobile phone and a computer. The variable was dichotomised into having at least one of the assets (improved) or having none of the assets (poor) with the latter constituting the exposed group.

\section{Statistical analysis}

Descriptive statistics was calculated to estimate the prevalence of MHDs, violence exposure and participants' sociodemographic and psychosocial characteristics. The $\chi^{2}$ test was used to assess the relationship between the psychosocial characteristics and MHD experience. For the association between different forms of IPV (predictor variables) and the MHDs (outcome variables), bivariable and multivariable logistic regression analyses were performed. Possible confounders were considered based on statistical significance in bivariable analyses and theoretical reasons grounded in previous research. The final regression models were therefore adjusted for women and husband's education, social support, household assets, marital status and alcohol consumption. Potential interactions between variables in the final models were tested but no statistically significant interactions were present. All estimates from the multivariable logistic regression models are presented as adjusted ORs (aORs) with their $95 \%$ CIs. Finally, population attributable risk fractions (PAFs) for the effect of exposure to each of the forms of IPV during pregnancy on different MHDs were 
Table 1 Sociodemographic and psychosocial characteristics of the study population $(n=921)$

\begin{tabular}{|c|c|c|}
\hline Variable & Frequency & Per cent \\
\hline \multicolumn{3}{|l|}{ Age groups (years) } \\
\hline $15-25$ & 362 & 39.4 \\
\hline $26-36$ & 472 & 51.3 \\
\hline $37-47$ & 86 & 9.3 \\
\hline \multicolumn{3}{|l|}{ Marital status } \\
\hline $\begin{array}{l}\text { Single, divorced, widowed, } \\
\text { separated }\end{array}$ & 146 & 15.8 \\
\hline Married or cohabitating & 774 & 84.2 \\
\hline \multicolumn{3}{|l|}{ Highest attained level of education } \\
\hline Incomplete primary school & 417 & 50.1 \\
\hline $\begin{array}{l}\text { Complete primary school or } \\
\text { vocational training }\end{array}$ & 219 & 26.4 \\
\hline Secondary school or university & 195 & 23.5 \\
\hline \multicolumn{3}{|l|}{ Occupation } \\
\hline Skilled work, civil servant, student & 119 & 13.1 \\
\hline Non-skilled work & 528 & 58.3 \\
\hline Not employed, other occupation & 260 & 28.6 \\
\hline \multicolumn{3}{|l|}{ Social support } \\
\hline Good & 734 & 79.8 \\
\hline Poor & 186 & 20.2 \\
\hline \multicolumn{3}{|l|}{ Partner/husband's age (years) ${ }^{\star}$} \\
\hline $15-25$ & 129 & 20.9 \\
\hline $26-36$ & 446 & 72.4 \\
\hline$\geq 37$ & 41 & 6.7 \\
\hline \multicolumn{3}{|l|}{$\begin{array}{l}\text { Partner/husband's highest level of } \\
\text { education* }\end{array}$} \\
\hline Incomplete primary school & 283 & 42.9 \\
\hline $\begin{array}{l}\text { Complete primary school or } \\
\text { vocational training }\end{array}$ & 248 & 37.6 \\
\hline Secondary school or university & 128 & 19.5 \\
\hline \multicolumn{3}{|l|}{ Total household monthly income } \\
\hline$<$ FRW17500† (\$30) & 258 & 29.9 \\
\hline FRW17501-FRW35999 (\$30-\$60) & 240 & 27.8 \\
\hline$\geq$ FRW36 $000(\$ \geq 60)$ & 364 & 42.2 \\
\hline \multicolumn{3}{|l|}{$\begin{array}{l}\text { Intimate partner violence during } \\
\text { pregnancy }\end{array}$} \\
\hline Physical & 94 & 10.2 \\
\hline Psychological & 157 & 17.0 \\
\hline Sexual & 89 & 9.7 \\
\hline Controlling behaviour & 163 & 17.6 \\
\hline \multicolumn{3}{|l|}{ Mental health disorders } \\
\hline $\begin{array}{l}\text { Major depressive episode in the } \\
\text { past } 2 \text { weeks }\end{array}$ & 110 & 11.9 \\
\hline $\begin{array}{l}\text { Major depressive episode in earlier } \\
\text { periods }\end{array}$ & 88 & 9.5 \\
\hline Generalised anxiety disorder & 182 & 19.7 \\
\hline
\end{tabular}

Continued
Table 1 Continued

\begin{tabular}{lcc}
\hline Variable & Frequency & Per cent \\
\hline Suicide risk & 98 & 10.8 \\
Post-traumatic stress disorder & 74 & 8.0 \\
$\begin{array}{l}\text { Suffering from any mental } \\
\text { condition }\end{array}$ & 247 & 27.1 \\
\hline
\end{tabular}

*Data were missing as some women could not report their husband/partner's age and level of education.

†Francs Rwandais.

calculated using the following formula: $\mathrm{PAF}=\mathrm{P}_{1}(\mathrm{aOR}-1)$ / $(\mathrm{aOR})$ where $\mathrm{P}_{1}=$ proportion of women with any of the MHDs who reported exposure to physical, psychological or sexual violence, or controlling behaviour during pregnancy; $\mathrm{aOR}=\mathrm{aOR}$ for the association between the four forms of IPV and the MHD of interest. The formula takes potential confounding into account and allows for adjusted estimates. ${ }^{35}$ The PAFs represent the excess of prevalent cases of MHDs in the study population that can be attributed to IPV exposure and could thus be avoided if no physical violence, psychological violence, sexual violence or controlling behaviour were present. All the analyses were performed using the Statistical Package of Social Sciences V.25.0 for Windows (SPSS).

\section{Ethical considerations}

Participation was voluntary and no remuneration was paid for participating in the study. Before the interview, the interviewer explained in detail the content of the questionnaire, informed the participants on confidentiality of their responses and of their free choice to withdraw at any time during the study without any consequence. For the protection of the interviewed women in the households and to maintain confidentiality, only one woman in each household was interviewed. The interview was conducted in privacy where no one else was able to overhear the conversation. In case the partner/husband could not leave the household at the time of the interview, the woman to be interviewed would be revisited later. Because MHDs and IPV are sensitive issues, the participants were informed that those in need of any kind of assistance could receive it at a nearby health centre or hospital that was informed in advance about the study.

\section{Patient and public involvement}

No Patients were involved. Study findings will be presented to stakeholders, including local community groups at national conferences and community meetings.

\section{RESULTS}

Sociodemographic and psychosocial characteristics, IPV and MHDs

Most participants were of low socioeconomic status, had not completed primary school and were engaged 
in non-skilled work (table 1). The mean time since childbirth and the time of the interview was 7.1 months (range: 1.4-14.3). The majority were married or cohabiting $(84.2 \%, \mathrm{n}=774)$. Just over $20 \%$ of the participants $(\mathrm{n}=186)$ had poor social support. Of all participating women, $10.2 \% \quad(n=94)$ had been subjected to physical violence, $17 \%(\mathrm{n}=157)$ to psychological violence, $9.7 \% \quad(\mathrm{n}=89)$ to sexual violence and $17.6 \% \quad(\mathrm{n}=163)$ to controlling behaviour during pregnancy. Suicidal ideation was reported in $10.8 \%(\mathrm{n}=98)$ of the participants, and $27.1 \% \quad(n=247)$ had experienced at least one of the MHDs. Living in Kigali city, being single or divorced, having poor social support and lower socioeconomic status were associated with experiencing an MHD ( $<<0.05$, table 2$)$.

\section{Associations between IPV during pregnancy and MHDs}

After adjusting for potential confounders, multivariable logistic regression showed that exposure to physical, sexual or psychological violence and controlling behaviour during pregnancy were associated with the four MHDs investigated in this study (table 3). For physical, psychological and sexual violence, the associations were strongest with PTSD, with aORs of 4.52 (95\% CI: 2.14 to 9.58$), 6.29$ (95\% CI: 3.18 to 12.46$)$ and 6.22 (95\% CI: 2.98 to 12.92), respectively. The four forms of IPV exposure were strongly associated with suicidal ideation with aORs of 3.16 (95\% CI: 1.53 to 6.52$)$, 2.89 (95\% CI: 1.51 to 5.55 ) and 3.04 (95\% CI: 1.40 to 6.60 ) for exposure to physical, sexual or psychological violence, respectively.

Table 2 Participants' characteristics by mental health disorder $(n=921)^{\star}$

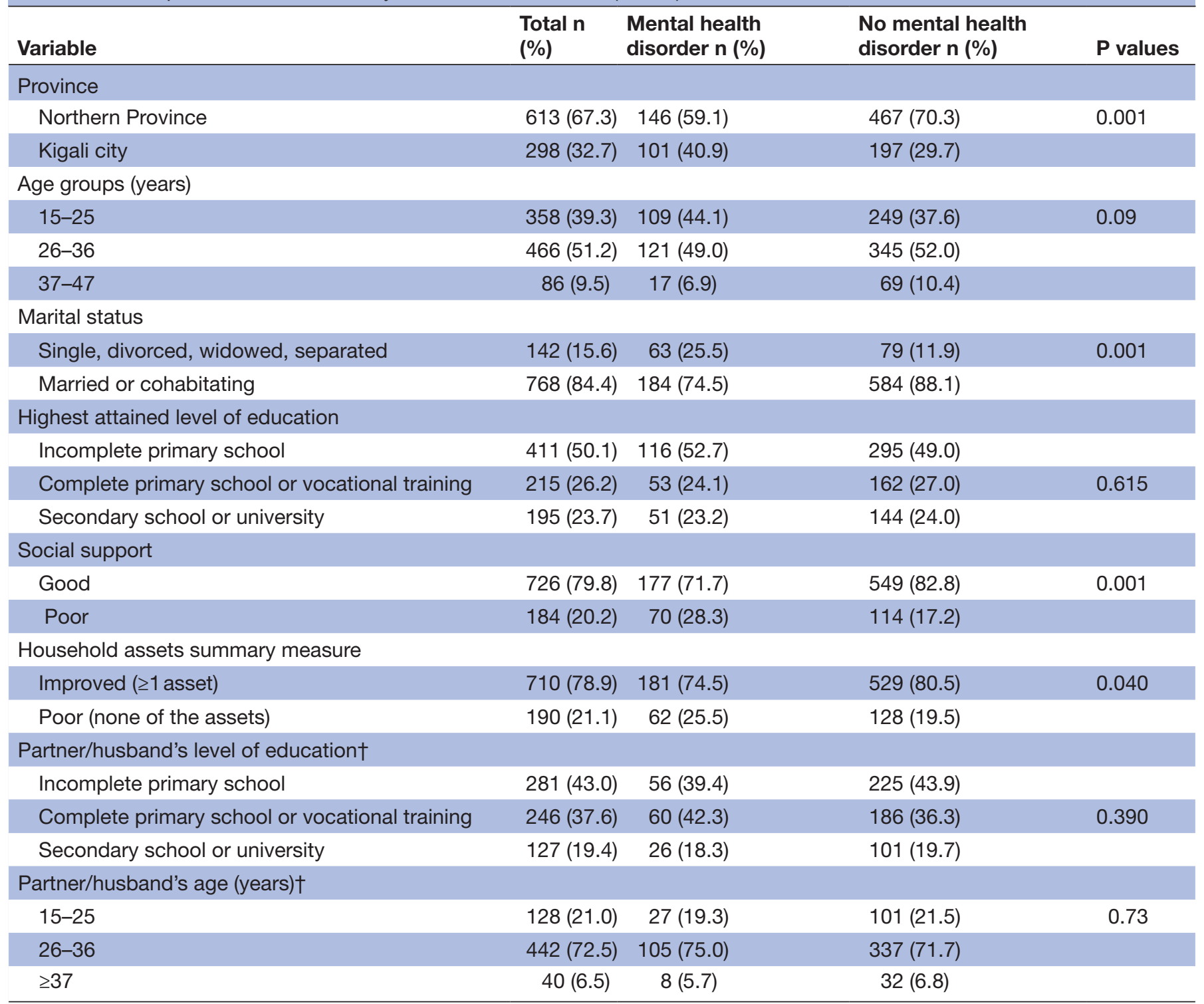

${ }^{*} \mathrm{P}$ values are from Pearson's $\chi^{2}$ test and show the relationship between participants' characteristics and having a mental health disorder (MHD). Having an MHD was defined as having at least one of the MHDs that is, the major depressive episode in the past 2 weeks or in earlier periods, generalised anxiety disorder, suicidal ideation or post-traumatic stress disorder.

†Data were missing as some women could not report their husband/partner's age and level of education. 
The likelihood of meeting diagnostic criteria for suicidal ideation was higher among women who reported controlling behaviour compared with those who did not, with an aOR of 6.28 (95\% CI: 3.20 to 12.33). Controlling behaviour had the largest estimates with each of the MHDs, the strongest association being with major depressive episode in earlier periods: aOR=9.17 (95\% CI: 4.22 to 19.93). In the final adjusted models most associations with sociodemographic and psychosocial characteristics were nearly fully attenuated, except for social support which remained statistically significant in all models (estimates not shown).

\section{Population attributable fraction}

aORs and proportions of participants with MHDs who suffered from IPV during pregnancy were used to calculate PAFs that could be attributed to physical, psychological or sexual violence and controlling behaviour in the study population. For all the MHDs, the PAFs attributed to controlling behaviour were the highest: $42 \%$ for major depressive episode in the past 2 weeks, $48 \%$ for major depressive episode in earlier periods, $36 \%$ for generalised anxiety disorder, $38 \%$ for suicidal ideation and $44 \%$ for PTSD. For major depressive episode in the past 2 weeks, the PAF attributed to physical violence was $19 \%$ and to psychological violence 25\%. The PAF attributed to sexual violence was highest among those participants with PTSD $(28 \%)$ and lowest (13\%) among those with major depressive episode in the past 2 weeks. For suicide ideation, the PAFs attributed to physical, psychological or sexual violence were $15 \%, 21 \%$ and $16 \%$, respectively (table 4 ).

\section{DISCUSSION}

In this study, we found that non-psychotic MHDs are common after childbirth among Rwandan women. Furthermore, the four forms of IPV perpetrated against pregnant women during pregnancy are associated with the occurrence of these disorders. Studies simultaneously investigating the prevalence of all types of MHDs during pregnancy and after childbirth are rare in LICs. Nevertheless, the available publications have shown the presence of depressive disorders, PTSD and anxiety symptoms with varying prevalence rates. ${ }^{2636-38}$ A study that included 1180 pregnant antenatal care patients in Tanzania demonstrated that the prevalence rate for depression was $55 \%, 23 \%$ for anxiety and $13 \%$ for PTSD. ${ }^{26}$ These estimates are higher than ours, but this is expected considering that the study used a different sample and did not make any distinction between depressive disorders during different time periods. Another study comprising 376 pregnant women from South Africa showed higher prevalence rates of MHDs than in our study. ${ }^{38}$ The differences in results might be attributable to the South Africa study only including women from urban areas; we similarly observed in the present study that women living in Kigali city were more likely to meet diagnostic criteria for an MHD than women from rural areas. However, the 
Table 4 Population attributable fractions of mental health disorder due to exposure to intimate partner violence during pregnancy $(n=921)^{*}$

\begin{tabular}{llllll}
\hline $\begin{array}{l}\text { Form of intimate } \\
\text { partner violence }\end{array}$ & $\begin{array}{l}\text { Major depressive } \\
\text { episode in the } \\
\text { past 2 weeks }\end{array}$ & $\begin{array}{l}\text { Major depressive } \\
\text { episode in earlier } \\
\text { periods }\end{array}$ & $\begin{array}{l}\text { Generalised } \\
\text { anxiety disorder }\end{array}$ & $\begin{array}{l}\text { Suicide } \\
\text { ideation }\end{array}$ & $\begin{array}{l}\text { Post-traumatic } \\
\text { stress disorder }\end{array}$ \\
\hline Physical violence & 0.19 & 0.22 & 0.08 & 0.15 & 0.19 \\
Psychological violence & 0.25 & 0.29 & 0.21 & 0.21 & 0.35 \\
Sexual violence & 0.13 & 0.16 & 0.15 & 0.16 & 0.28 \\
Controlling behaviour & 0.42 & 0.48 & 0.36 & 0.38 & 0.44 \\
\hline
\end{tabular}

${ }^{*}$ Calculated from adjusted ORs derived from the final multivariable logistic regression models.

relatively lower prevalence rates of MHDs in our study may indicate that many of the efforts to improve mental healthcare following the 1994 genocide in Rwanda are starting to bear fruit. ${ }^{39}$

Our results indicate that women exposed to IPV during pregnancy were more likely to have any of the non-psychotic MHDs (ie, depressive episodes during the past 2 weeks before the interview and earlier in life, generalised anxiety disorder, suicide ideation and PTSD) than those not exposed to IPV. Our findings add to a growing body of evidence showing a negative impact of IPV during pregnancy on antenatal and postnatal mental health. ${ }^{1040-42} \mathrm{~A}$ systematic review assessing determinants of non-psychotic common perinatal mental disorders in LMICs shows that women experiencing IPV were at a higher risk, with ORs ranging from 2.11 to $6.75 .{ }^{10}$ The magnitude of the impact is similar to the estimates for sexual, physical and psychological violence found in our study. The effect of partner's controlling behaviour on women's mental health during and after pregnancy has not been studied in LICs. Nevertheless, the strong association of controlling behaviour during pregnancy with MHDs in the perinatal period observed in this study is not surprising given that studies in similar settings have consistently shown that controlling behaviour was far more common than other forms of violence. ${ }^{234}$ Our results emphasise the need to recognise the severity of controlling behaviour and rectify any misleading perception that it is less harmful than physical or sexual violence. Although the underlying mechanisms through which IPV may lead to MHDs are not fully understood, violent experiences have been shown to cause neuroendocrine dysregulation which can trigger a range of conditions, including MHDs. ${ }^{44}$ The strong independent association of social support with all the MHDs reported in this study confirms previous findings showing that poor social support is an important risk factor for MHDs during the perinatal period. ${ }^{38} 45$

Finally, we have shown the excess of prevalent cases of different MHDs that can be attributed to exposure to the four forms of IPV. Although these are theoretical calculations, they demonstrate the detrimental role that IPV exposure plays during pregnancy in the occurrence of non-psychotic MHDs in women. The PAFs are plausible estimations of the magnitude of such disorders that could potentially be avoided if there were no IPV in the population.

\section{Methodological considerations}

The strengths of this study are the large sample size, the low non-response rate and the use of internationally recognised instruments to investigate MHDs and IPV, including controlling behaviour. Furthermore, Rwanda is a homogenous society, and therefore we believe that the findings are generalisable to the entire country in women who have just given birth. However, this study has limitations. First because of cultural beliefs and the sensitive nature of both MHDs and IPV, possibility of under-reporting of some events cannot be dismissed. Nevertheless, data collection was conducted with utmost care by a team of experienced medical personnel who were of the same sex and of similar age as the participants. This has been shown to improve the accuracy of reporting in interviews. ${ }^{46}$ Second, because the design was cross-sectional, we are unable to draw any causal inferences. Moreover, pregnant women's health and life circumstances vary considerably between nations. Our findings may therefore not be generalisable to women from other countries. Finally, data were collected retrospectively from respondents who gave birth between 1 and 13 months before the interview. This time interval may have resulted in recall bias and underestimation of prevalence rates as incidences of MHDs have generally been shown to peak immediately after childbirth and start to decline 6 months post partum. ${ }^{47}$ However, $52 \%$ of the participants had given birth $\leq 6$ months before the interview suggesting that this time frame may not be a serious concern.

\section{CONCLUSION}

Non-psychotic MHDs are common among Rwandan women during and after pregnancy, and IPV plays a key role in their occurrence. We suggest that MHDs and IPV should be integrated into the perinatal health assessment package and that antenatal care providers are regularly trained and have sufficient abilities so that they can identify and manage cases of IPV and MHDs correctly.

Community-based healthcare services aiming at increasing awareness and early identification of IPV and 
MHDs during the perinatal period need to educate and train CHWs, nurses and midwives. Community discussions on non-psychotic MHDs should be instituted and scaled up in all villages to reduce the stigma. Further research is needed to fully understand what screening tools and measures that could be used to identify MHDs early through ANC services and CHWs. Finally, strategies that have been put in place to reduce poverty and promote gender equality and social support should be intensified.

Acknowledgements We gratefully acknowledge the contribution of all participating women who welcomed us into their homes and gave their valuable time to answer our questions. We are also grateful to the Section for Epidemiology and Social Medicine (EPSO), University of Gothenburg and the School of Public Health, College of Medicine and Health Sciences, University of Rwanda for all their support.

Contributors GK, IM and AAR designed the study. GK, IM, AAR and JN developed part of the study questionnaire. AAR coordinated and participated in piloting and data collection activities and performed the statistical analyses with the assistance of GK and JN. The manuscript was drafted and written by AAR with contributions from GK, IM, JN and KG.

Funding This study forms part of the Maternal Health Research Programme (MaTHeR) undertaken by the University of Rwanda in collaboration with the University of Gothenburg and Umeå University in Sweden. The Study was made possible by financial support from The Swedish International Development Cooperation Agency (SIDA).

Competing interests None declared.

Patient consent Not required.

Ethics approval Institutional Review Board of the College of Medicine and Health Sciences, University of Rwanda and National Institute of Statistics of Rwanda (No: 0425/2014/10/NISR).

Provenance and peer review Not commissioned; externally peer reviewed. Data sharing statement № additional data are available.

Open access This is an open access article distributed in accordance with the Creative Commons Attribution Non Commercial (CC BY-NC 4.0) license, which permits others to distribute, remix, adapt, build upon this work non-commercially, and license their derivative works on different terms, provided the original work is properly cited and the use is non-commercial. See: http://creativecommons.org/ licenses/by-nc/4.0/

(c) Article author(s) (or their employer(s) unless otherwise stated in the text of the article) 2018. All rights reserved. No commercial use is permitted unless otherwise expressly granted.

\section{REFERENCES}

1. WHO. Mental Health. http://www.who.int/mental_health/maternalchild/maternal_mental_health/en/ (accessed Nov 2017).

2. Atif N, Lovell K, Rahman A. Maternal mental health: The missing " $\mathrm{m}$ " in the global maternal and child health agenda. Semin Perinatol 2015;39:345-52.

3. Alder J, Fink N, Bitzer J, et al. Depression and anxiety during pregnancy: a risk factor for obstetric, fetal and neonatal outcome? A critical review of the literature. J Matern Fetal Neonatal Med 2007;20:189-209.

4. Sherer ML, Posillico CK, Schwarz JM. The psychoneuroimmunology of pregnancy. Front Neuroendocrinol 2017.

5. Albaugh AS, Friedman SH, Yang SN, et al. Attendance at mental health appointments by women who were referred during pregnancy or the postpartum period. J Obstet Gynecol Neonatal Nurs 2018;47.

6. Howard LM, Molyneaux E, Dennis CL, et al. Non-psychotic mental disorders in the perinatal period. Lancet 2014;384:1775-88.

7. Wisner KL, Sit DK, McShea MC, et al. Onset timing, thoughts of self-harm, and diagnoses in postpartum women with screen-positive depression findings. JAMA Psychiatry 2013;70:490-8.

8. UNFPA. Maternal mental health and child health and development in low and middle income countries. 2016;12 http://www.who.int/ mental_health/prevention/suicide/mmh_jan08_meeting_report.pdf.
9. Hoirisch-Clapauch S, Brenner B, Nardi AE. Adverse obstetric and neonatal outcomes in women with mental disorders. Thromb Res 2015;135 Suppl 1:S60-S63.

10. Fisher J, Cabral de Mello M, Patel V, et al. Prevalence and determinants of common perinatal mental disorders in women in low- and lower-middle-income countries: a systematic review. Bull World Health Organ 2012;90:139-49.

11. Biratu A, Haile D. Prevalence of antenatal depression and associated factors among pregnant women in Addis Ababa, Ethiopia: a crosssectional study. Reprod Health 2015;12:99.

12. Khan AM, Flora MS. Maternal common mental disorders and associated factors: a cross-sectional study in an urban slum area of Dhaka, Bangladesh. Int J Ment Health Syst 2017;11:23.

13. Patel V, Abas M, Broadhead J, et al. Depression in developing countries: lessons from Zimbabwe. BMJ 2001;322:482-4.

14. Chisholm CA, Bullock L, Ferguson JEJ. Intimate partner violence and pregnancy: epidemiology and impact. Am J Obstet Gynecol 2017;217:141-4.

15. Machisa MT, Christofides N, Jewkes R. Structural pathways between child abuse, poor mental health outcomes and male-Perpetrated Intimate Partner Violence (IPV). PLoS One 2016;11:e0150986.

16. Nakku JE, Okello ES, Kizza D, et al. Perinatal mental health care in a rural African district, Uganda: a qualitative study of barriers, facilitators and needs. BMC Health Serv Res 2016;16:295.

17. Bodnar-Deren S, Klipstein K, Fersh M, et al. Suicidal ideation during the postpartum period. J Womens Health 2016;25:1219-24.

18. Rugema L, Mogren I, Ntaganira J, et al. Traumatic episodes and mental health effects in young men and women in Rwanda, 17 years after the genocide. BMJ Open 2015;5:e006778.

19. Rieder $\mathrm{H}$, Elbert T. Rwanda - lasting imprints of a genocide: trauma, mental health and psychosocial conditions in survivors, former prisoners and their children. Confl Health 2013;7:6.

20. Eytan A, Munyandamutsa N, Nkubamugisha PM, et al. Long-term mental health outcome in post-conflict settings: Similarities and differences between Kosovo and Rwanda. Int J Soc Psychiatry 2015;61:363-72.

21. Rugema L, Krantz G, Mogren I, et al. "A constant struggle to receive mental health care": health care professionals' acquired experience of barriers to mental health care services in Rwanda. BMC Psychiatry 2015;15:314.

22. WHO. Intimate partner and sexual violence against women. Factsheets http://www.who.int/mediacentre/factsheets/fs239/en/ (accessed Nov 2017).

23. Rurangirwa AA, Mogren I, Ntaganira J, et al. Intimate partner violence among pregnant women in Rwanda, its associated risk factors and relationship to ANC services attendance: a population-based study. BMJ Open 2017;7:e013155.

24. Desmarais SL, Pritchard A, Lowder EM, et al. Intimate partner abuse before and during pregnancy as risk factors for postpartum mental health problems. BMC Pregnancy Childbirth 2014;14:132.

25. Umubyeyi A, Mogren I, Ntaganira J, et al. Intimate partner violence and its contribution to mental disorders in men and women in the post genocide Rwanda: findings from a population based study. BMC Psychiatry 2014;14:315.

26. Mahenge B, Likindikoki S, Stöckl H, et al. Intimate partner violence during pregnancy and associated mental health symptoms among pregnant women in Tanzania: a cross-sectional study. BJOG 2013;120:940-7

27. Seth P, Kidder D, Pals S, et al. Psychosocial functioning and depressive symptoms among HIV-positive persons receiving care and treatment in Kenya, Namibia, and Tanzania. Prev Sci 2014;15:318-28.

28. Tufton N, Patel RR. Prevalence of hypertensive disorders in a prenatal clinic in Zanzibar. Int J Gynaecol Obstet 2011;112:69-70.

29. Rurangirwa AA, Gaillard R, Steegers EA, et al. Hemodynamic adaptations in different trimesters among nulliparous and multiparous pregnant women; the Generation R study. Am J Hypertens 2012;25:892-9.

30. National Institute of Statistics of Rwanda. Fourth population and housing census. http://statistics.gov.rw/survey-period/fourthpopulation-and-housing-census-2012 (accessed oct 2017).

31. Sheehan DV, Lecrubier Y, Sheehan KH, et al. The Mini-International Neuropsychiatric Interview (M.I.N.I.): the development and validation of a structured diagnostic psychiatric interview for DSM-IV and ICD10. J Clin Psychiatry 1998;59 Suppl 20:22quiz 34-3357.

32. WHO. Multi-Country Study on women's Health and Life Experiences 2005, 2017. http://www.spc.int/hdp/index2.php?option=com_ docman\&task=doc_view\&gid=52\&ltem $=4$.

33. Garcia-Moreno C, Jansen HA, Ellsberg M, et al. Prevalence of intimate partner violence: findings from the WHO multi-country study on women's health and domestic violence. Lancet 2006;368:1260-9. 
34. Saddki N, Sulaiman Z, Ali SH, et al. Validity and reliability of the Malay version of WHO Women's Health and Life Experiences Questionnaire. J Interpers Violence 2013;28:2557-80.

35. Rockhill B, Newman B, Weinberg C. Use and misuse of population attributable fractions. Am J Public Health 1998;88:15-19.

36. Heim L, Schaal S. Rates and predictors of mental stress in Rwanda: investigating the impact of gender, persecution, readiness to reconcile and religiosity via a structural equation model. Int $J$ Ment Health Syst 2014;8:37.

37. Ng LC, Harerimana B. Mental health care in post-genocide Rwanda: evaluation of a program specializing in posttraumatic stress disorder and substance abuse. Glob Ment Health 2016;3.

38. van Heyningen T, Honikman S, Myer L, et al. Prevalence and predictors of anxiety disorders amongst low-income pregnant women in urban South Africa: a cross-sectional study. Arch Womens Ment Health 2017;20:765-75.

39. Ministry of Health Rwanda. National mental health policy in Rwanda. http://www.moh.gov.rw/fileadmin/templates/Docs/Posted-NationalMental-health-Policy-1.pdf (accessed Dec 2017).

40. Kabir ZN, Nasreen HE, Edhborg M. Intimate partner violence and its association with maternal depressive symptoms 6-8 months after childbirth in rural Bangladesh. Glob Health Action 2014;7:24725.
41. de Oliveira Fonseca-Machado M, Camargo Alves L, Scotini Freitas $\mathrm{P}$, et al. Mental health of women who suffer intimate partner violence during pregnancy. Invest Educ Enferm 2014;32:291-305.

42. Hooker L, Samaraweera NY, Agius PA, et al. Intimate partner violence and the experience of early motherhood: A cross-sectional analysis of factors associated with a poor experience of motherhood. Midwifery 2016;34:88-94.

43. Kapiga S, Harvey S, Muhammad AK, et al. Prevalence of intimate partner violence and abuse and associated factors among women enrolled into a cluster randomised trial in northwestern Tanzania. BMC Public Health 2017;17:190.

44. Crofford LJ. Violence, stress, and somatic syndromes. Trauma Violence Abuse 2007;8:299-313.

45. Anderson FM, Hatch SL, Comacchio C, et al. Prevalence and risk of mental disorders in the perinatal period among migrant women: a systematic review and meta-analysis. Arch Womens Ment Health 2017;20:449-62.

46. Guest G, Bunce A, Johnson L, et al. Fear, hope and social desirability bias among women at high risk for HIV in West Africa. J Fam Plann Reprod Health Care 2005;31:285-7.

47. Dikmen-Yildiz P, Ayers S, Phillips L. Depression, anxiety, PTSD and comorbidity in perinatal women in Turkey: A longitudinal populationbased study. Midwifery 2017;55:29-37. 